\title{
Access to remedy in transnational development projects: the need for effective and comprehensive remedy ecosystems
}

\author{
Martijn Scheltema* \\ Professor at Erasmus University Rotterdam, partner at Pels Rijcken and chair of the dispute-resolution mechanism of the \\ Dutch IRBC Agreements in the Textile and Natural Stone sector, The Netherlands \\ ${ }^{*}$ Corresponding author. E-mail: m.scheltema@law.eur.nl
}

\section{Introduction}

It is observed in the Introduction of this special issue that the rule of law has been an integral part of the development of democratic systems of government in national states and features powerfully within contemporary 'good-governance' promotion in the Global South by development financial institutions (DFIs). ${ }^{1}$ However, the rule of law is predominantly used to emphasise the importance of stability of contract and protection of property in connection with transnational development projects (TDPs) and does not so much focus on the general stability of (e.g. indigenous) rights, access to justice and fairness. ${ }^{2}$ Thus, it is important to deviate from a narrow interpretation of the rule of law and include the role of all types of actors in safeguarding this rule of law. ${ }^{3}$

This contribution focuses on the improvement of access to justice for those whose human rights (as part of the rule of law) are impacted by TDPs (often indigenous or vulnerable groups). It tries to contribute to more successful TDPs by trying to find the best way to act in the interest of companies, public actors and affected communities. The aim is to find an effective and comprehensive remedy system that will be acceptable to all parties involved and that could be achievable in the current landscape of development projects. The contribution first identifies the challenges for access to justice for these groups in TDPs as have been well elaborated by Bhatt (2020). It then focuses on the question of whether (a combination of) the current mechanisms could satisfy these needs and, if not, the way in which access to remedy ecosystems could be established that addresses these challenges more effectively.

\section{Challenges for access to remedy in TDPs}

Vulnerable or indigenous peoples face various challenges in connection with access to remedy. Often, these indigenous or vulnerable peoples are not, poorly or too late consulted on a project (Bhatt, 2020, p. 36) and even less so on their needs in connection with access to remedy.

To date, several, mainly dialogue-based (non-binding) complaint mechanisms exist at either the operational (local) level, the development bank ${ }^{4}$ or the Worldbank level. ${ }^{5}$ Obviously, they may access

\footnotetext{
${ }^{1}$ See para. 2.1 .

${ }^{2}$ See para. 2.1 of the Introduction to this Special Issue.

${ }^{3} \mathrm{Cf}$. the Introduction to this Special Issue, para. 3 .

${ }^{4}$ See e.g. for FMO (the Dutch Development bank), https://www.fmo.nl/independent-complaints-mechanism and, for the European Development bank, https://www.ebrd.com/work-with-us/project-finance/project-complaint-mechanism/ipamregister.html (both accessed 1 February 2021).

${ }^{5} \mathrm{CAO}$ compliance ombudsman. See on this mechanism http://www.cao-ombudsman.org/ (accessed 1 February 2021).

(C) The Author(s), 2021. Published by Cambridge University Press. This is an Open Access article, distributed under the terms of the Creative Commons Attribution-NonCommercial-NoDerivatives licence (http://creativecommons.org/licenses/by-nc-nd/4.0/), which permits noncommercial re-use, distribution, and reproduction in any medium, provided the original work is unaltered and is properly cited. The written permission of Cambridge University Press must be obtained for commercial re-use or in order to create a derivative work.
} 
national courts regarding claims against the entity (often a special-purpose vehicle) that operates the project or against the national government. That said, these mechanisms are often deployed in isolation and connected to one actor.

However, as Bhatt shows, these projects are governed by contractual frameworks that create interdependency between the various actors and may require solutions to which all these actors consent or that can be imposed on them in order to provide effective access to remedy (Bhatt, 2020, pp. 87-88, $103,138-139,196)$. Beyond this, time pressure to get deals done and to build a predictable revenue flow may result in lower priority of the protection of rights of indigenous or vulnerable communities and tick-the-box exercises (Bhatt, 2020, pp. 36-37, 55 62-68, 96). States may also refuse to enforce court decisions, take a very long time to enforce them or have economic preferences other than those of indigenous communities, and DFIs may claim immunity in litigation against them (Bhatt, 2020, pp. 62, 69-71, 75).

\section{Improving access to remedy for rights-holders}

\subsection{Introduction}

The previous section highlighted issues raised by Bhatt that are shown to hamper access to remedy for rights-holders in connection with project finance. It is quite clear that remedy is often partial at best. ${ }^{6}$ A lack of sensitivity or responsiveness of many mechanisms to their legal, regulatory, social and cultural contexts and a lack of co-operation between developers and operators of mechanisms in specific contexts and cases result in unclear and incoherent processes, inefficiencies and other barriers for rights-holders. ${ }^{7}$ Developers and operators of these mechanisms may need to give much greater emphasis on the needs, expectations and perspectives of the people for whom these mechanisms are intended, for which recognising different ways in which meaningful stakeholder engagement is fundamental to meeting each of the UNGP's ${ }^{8}$ effectiveness criteria. ${ }^{9}$ This shows that comprehensive solutions that provide more complete remedy to rights-holders are often challenging to reach through the existing dispute-resolution systems. It is exacerbated because DFIs increasingly tend to finance governments in order to enable them to initiate projects instead of directly financing projects. This often implies that less independent control is exercised over such projects. Thus, this paper will explore which more effective 'remedy ecosystems' would be conceivable to provide much more complete and comprehensive remedy. ${ }^{10}$

\subsection{Access-to-remedy needs assessment}

To start with, it is important to understand the initial access-to-remedy needs of rights-holders. Not only the operating company and the financiers, but also the host government should have an interest

\footnotetext{
${ }^{6}$ This may be caused by a limited mandate, limited resources or both. See regarding access to remedy in general: Improving accountability and access to remedy for victims of business-related human rights abuse through non-state-based grievance mechanisms, Report of the United Nations High Commissioner for Human Rights, 19 May 2020, A/HRC/44/32 (hereafter “ARP III”), available at https://undocs.org/A/HRC/44/32 (accessed 1 February 2021), under 7. See also Bhatt (2020, pp. 8387, 141, 169, 171, 186); Working Group Enabling Remediation of the Dutch International Responsible Business Conduct Agreement in the banking sector (hereinafter referred to as "Enabling Remediation"), p. 22, available at https://www.imvoconvenanten.nl/en/banking/about-this-agreement/-/media/07CD109E4E15451AB96D8B2DC210713E.ashx (accessed 1 February 2021).

${ }^{7}$ See ARP III, under 8.

${ }^{8}$ United Nations Guiding Principles on Business Human Rights and especially UNGP 31, available at https://www.ohchr. org/documents/publications/guidingprinciplesbusinesshr_en.pdf (accessed 1 February 2021).

${ }^{9}$ See ARP III, under 11.

${ }^{10}$ See also Recommendation 3 of the Working Group Enabling Remediation of the Dutch International Responsible Business Conduct Agreement in the banking sector, available at https://www.imvoconvenanten.nl/-/media/imvo/files/banking/news/2019/enabling-remediation.pdf?la=en\&hash=3F2B0677E6B806EC7FDFB721BBFC8810 (accessed 1 February 2021).
} 
in such an assessment. ${ }^{11}$ It is an element of the government's duty to protect human rights and to secure access to remedy as well as an element of human rights due diligence to be undertaken by the operating company and financiers, also to secure the longer-term exploitability of the project. This especially goes for DFIs that regularly engage in projects involving higher human-rights-related risks.

Usually, human rights impact assessments are undertaken by the operating companies or the project sponsor, ${ }^{12}$ although often as part of a broader environmental assessment required for government permits. However, these assessments often neglect the need for meaningful consultation of all relevant stakeholders and not only those pretending to represent them (such as local chiefs) and, thus, these assessments may neglect the interests of indigenous, marginalised or vulnerable people by doing so (cf. Bhatt, 2020, pp. 134-135, 153). ${ }^{13}$ That said, such an assessment, even if well conducted, is not enough to assess the access-to-remedy needs of local rights-holders. For example, pre-existing issues may be present regarding land rights because of discussions over informal land rights, indigenous rights on the land or a pre-existing civil war. Furthermore, the influx of migrant workers is often triggered by these large projects. This may cause tensions in local communities. Beyond this, the question is which rights-holders should be included in the access-to-remedy functions. For example, if a hydropower facility is built, should only rights-holders in the direct vicinity of the project who are confronted with resettlement issues be involved or also those downstream, where water levels may be reduced or a pollution risk emerges, as well as upstream, where rights-holders may no longer have the opportunity to cross the river with their cattle? Sometimes, it is also unclear which entity resettles people and this should be clarified as part of the access-to-remedy needs (Bhatt, 2020, p. 82). Finally, the government may have an interest in the project and may put this interest above that of local rights-holders, for example in the permitting process. Thus, it needs to be assessed, preferably by an independent entity, what kind of dispute-resolution system local rights-holders feel would be necessary to deal with these issues and also what kind of dispute-resolution systems are still lacking or are not sufficient to solve issues. ${ }^{14}$ For example, administrative proceedings against permitting by the government may offer protection against government abuse in one country, whereas this is different in weak-governance zones or when corruption issues exist. Thus, the access-to-remedy needs assessment may reveal additional mechanisms or improvement of existing mechanisms may be required. ${ }^{15}$ Although the access-to-remedy needs assessments should be undertaken before the start of the project and should be sufficiently broad, regular evaluations of these assessments involving relevant stakeholders during the project are required.

Furthermore, it is important that the financiers (e.g. DFIs, commercial lenders and credit insurers) of the project become aware of these access-to-remedy needs in order to take them into account in the decision regarding the project and to incentivise an effective remedy ecosystem throughout the project

\footnotetext{
${ }^{11}$ Cf. ARP III, Annexes 15.1(c), 16.1(c); Enabling Remediation, pp. 26, 27. This is also consistent with the observation in the ARP III report that governments should conduct a review (consulting appropriately and meaningfully with stakeholders) on the different ways in which non-state-based mechanisms may complement the effective implementation of the state's international legal obligations and policy commitments with regard to accountability and remedy for business-related human rights harm and consequently inform and continuously improve the state's strategies. See ARP III, Annexes 1.1 (b), 1.2(a), 4.1(c).

${ }^{12}$ See e.g. Bhatt (2020, p. 79). Cf. Equator Principles 2 and 7 (requiring independent review), available at https://equatorprinciples.com/wp-content/uploads/2020/05/The-Equator-Principles-July-2020-v2.pdf (accessed 1 February 2021). Cf. also SBS Resolution no. 1928-2015 of the Peruvian Banking Authority, which requires banks to conduct impact assessments and community consultations before engaging in a project. A translation of this resolution is available at https://www.ifc. org/wps/wcm/connect/ca2b24bc-1aa9-41a2-9eb3-abc3219ebcd2/SBN_Regulation+for+Social+and+Environmental+Risk +Management.pdf?MOD=AJPERES\&CVID=kWtGcPU (accessed 1 February 2021).

${ }^{13}$ Carlos Jose Valderrama and Elise Groulx-Diggs, Mediating to avoid high financial risk, available at https://imimediation. org/2020/10/05/mediating-to-avoid-high-financial-risk/ (accessed 1 February 2021). Cf. Equator Principle 5, which requires stakeholder engagement in category A and B projects.

${ }^{14} \mathrm{Cf}$. in general ARP III, Annex 7.3.

${ }^{15} \mathrm{Cf}$. Enabling Remediation, Recommendation 2.
} 
if they engage. ${ }^{16}$ For example, the access-to-remedy needs assessment may reveal that mechanisms are needed to address previous resettlement undertaken by the government in order to facilitate the project. The financiers have in interest in knowing this and should make the closure of the deal dependent upon a solution (e.g. through an effective dispute-resolution mechanism). ${ }^{17}$ Furthermore, the access-to-remedy needs assessment can inform the project sponsors and financiers about the estimated time that it will take to solve (human-rights-related) issues. The project investment memorandum (PIM) ${ }^{18}$ in which the financiers are informed about the project may be a good document in which to include this assessment. At this point, they may decide not to engage if the assessment reveals that it is unlikely that existing or additional mechanisms are capable of solving the identified human rights issues. However, in several instances, DFIs or commercial banks become involved at a later stage of the project, for example when it has been completed by 80 per cent (cf. Bhatt, 2020, p. 113). Then, the question of whether or not an access-to-remedy assessment has been undertaken and, if so, its outcomes should be part of their investment decision. Financiers should also advise these assessments in their project advisory role as part of their human rights due diligence, especially regarding high-risk projects. ${ }^{19}$ Furthermore, states could make the access-to-remedy need assessments a requirement for a government permit. $^{20}$

Based on the foregoing, a project-level access-to-remedy needs assessment should clarify which existing mechanisms may play a role in solving human rights issues, either pre-existing or anticipated, which additional mechanisms are required, the needs of rights-holders to meaningfully access and engage in these mechanisms and an estimate of the time it will take to solve identified human rights issues. However, to date, very little expertise exists regarding these assessments of access-to-remedy needs, as they are currently mainly undertaken at the country, and not at the project, level. Thus, the development and capacity-building of these assessments is necessary. This should be actively promoted by DFIs, commercial banks, and host and home governments. Furthermore, the entities currently engaged by the operating company or project sponsor to undertake human rights impact assessments may not be best positioned to conduct an access-to-remedy needs assessment, as they may well be local independent facilitators with relevant knowledge of human and indigenous rights whom all relevant rights-holders trust, and they will need to be involved to undertake such an assessment through meaningful consultation with local stakeholders. ${ }^{21}$

Obviously, this raises the question of who should fund such assessments. If it is directly funded by the sponsoring company of the project (or the government), this may raise issues of independency and conflict of interest in connection with the outcomes. An independent globally operating trust fund (blind trust) funded by sponsors may be in the best position to fund such assessments. It includes the functions proposed by Bhatt in connection with assessing access-to-remedy needs and funding representation of rights-holders, ${ }^{22}$ but does not operate at the national or DFI institutional level. It operates globally, incorporating dedicated trusts for specific projects. Thus, it is more independent from actors involved in the projects, such as the host government or DFIs. Furthermore, it also funds the proposed remedy ecosystems that emerge from the access-to-remedy needs assessments and not only the access-to-remedy needs assessment itself and representation of rights-holders. The fund could receive a percentage of the envisaged project cost and, if the project is well managed, the operating company (or its beneficiaries) should be repaid the remaining amount in the trust

\footnotetext{
${ }^{16}$ Cf. Bhatt (2020, pp. 192-93); Enabling Remediation, p. 28.

${ }^{17}$ However, to date, some resistance seems to exist to include this requirement as a condition precedent. Cf. Bhatt (2020, p. 120).

${ }^{18}$ The PIM is a memorandum in which the sponsor sets out the key features of the project, including government permits, stabilisations clauses and other government assurances. DFIs decide to invest based on this memorandum.

${ }^{19}$ E.g. category A projects as defined in Principle 1 of the Equator Principles. However, it may be advisable to develop more widely accepted guidance on the definition of high-risk projects.

${ }^{20} \mathrm{Cf}$. in connection with establishing a grievance mechanism, see Bhatt (2020, p. 196, note 5).

${ }^{21}$ Cf. Equator Principle 7, which requires independent review of human rights impact assessments.

${ }^{22}$ Bhatt (2020, pp. 197-198) proposes another type of trust fund in connection with project finance.
} 
fund (the amount that has not been used to conduct the access-to-remedy needs assessment or to pay for mechanisms and representation of rights-holders to solve issues that have arisen). A globally operating trust fund may have the advantage vis-à-vis a project trust fund that this global trust fund oversees many of these assessments in multiple countries and projects, and may provide guidance and expertise in connection with undertaking such access-to-remedy assessments. It may also be seen as more independent and credible vis-à-vis the project sponsor than project-level trust funds. Alternatively, if multi-stakeholder initiatives are active at the project level, they may perform a comparable function, although they may lack the global experience and resource function that the global trust fund may have. Thus, a credible avenue to funding of access-to-remedy needs assessments may be developed and financiers could require such assessments to become part of the PIM and make it part of their decision to engage or of their advice in their project advisory role. They should bear in mind that badly managed disputes may escalate, and escalation tends to have a huge impact on the bankability of a project and on the reputation of the financiers.

\subsection{Dialogue-based solutions}

If the existing dispute-resolution systems are not sufficient, it is important to bridge this gap. Remedy ecosystems should be able to provide coherent and comprehensive solutions that may include remedy for local rights-holders involving all relevant actors. ${ }^{23}$ Usually, especially with more risky projects (e.g. the Equator Principles projects in the A and some in the B category), an operational-level grievance mechanism is created to deal with complaints against the company operating the project. $^{24}$ Furthermore, several DFIs, the World $\mathrm{Bank}^{25}$ (e.g. if the International Finance Corporation (IFC) or Multilateral Investment Guarantee Agency (MIGA), both part of the World Bank, is involved) and sometimes commercial banks have established complaint mechanisms for complaints directed towards those institutions. ${ }^{26}$ Sometimes, complaints against commercial banks are lodged with OECD National Contact Points. Beyond this, local courts and/or administrative procedural options exist to deal with disputes with the government. Finally, rights-holders may provide their views through a third-party submission in some investment arbitrations. ${ }^{27}$ However, accessibility to such mechanisms has proven a challenge for local rights-holders, most of the dispute-resolution systems involve only one or two relevant actors but not all, the relationship between mechanisms and independency is an issue (Van Putten, 2008, pp. 101, 249) and often complaints are no longer allowed in operational-level mechanisms if a large part of the loan is disbursed or when some time (e.g. two years) has lapsed after completion of the project.

Thus, a more comprehensive system may be needed that involves all stakeholders to enable effective remedies (a multi-stakeholder project-level grievance mechanism). For example, if it is revealed that land rights may be implicated after the start of the project and a more thorough impact assessment is necessary, then this decision should involve all relevant actors and not only the company running the project. If this impact assessment would delay the completion date of the project, the contractual mechanism usually imposes sanctions, such as penalty interest payments, suspending payments to the government or revocation of the project permit (Bhatt, 2020, pp. 92-93, 111, 152, 159-160). Thus, some parties, such as the financiers, but in some cases also the government, have means to enforce

\footnotetext{
${ }^{23}$ Cf. Enabling Remediation, pp. 22, 24, 26-28, 31, 32.

${ }^{24}$ See Equator Principle 6.

${ }^{25}$ The Compliance Advisor Ombudsman, information about whom is available at http://www.cao-ombudsman.org/ (accessed 1 February 2021).

${ }^{26}$ Cf. Enabling Remediation, p. 32. See also Van Putten (2008, p. 92).

${ }^{27}$ However, the procedural rules should allow for this (e.g. if the UNCITRAL Rules on Transparency are applicable, available at https://www.uncitral.org/pdf/english/texts/arbitration/rules-on-transparency/Rules-on-Transparency-E.pdf, or the ICSID rules apply, available at https://icsid.worldbank.org/resources/rules-and-regulations/convention/arbitration-rules (both accessed 1 February 2021)) and this does not provide remedy as such for the rights-holders, as they are not allowed to file any claims in such proceedings.
} 
timely completion of the project. It is self-evident that the company running the project will try to prevent such sanctions and, thus, has a huge (financial) interest in completing the project on time. Therefore, it may not conduct the human rights impact assessment properly in order to prevent delay. The implication of this is that the Free Prior and Informed Consent (FPIC) is not given and rights-holders do not have sufficient access to remedy. The only way to solve this issue would be to also make the other parties such as financiers and (if necessary) the government part of the dispute and involve them in the dispute-resolution system, which enables rights-holders to engage in an meaningful way, counters the power imbalance with the other stakeholders like DFIs and the host government, and is UNGP 31 compliant. ${ }^{28}$ The solution found in such a system may be that the financiers and the government consent to a postponement of the completion date without sanctions until the human rights impact assessment has been properly conducted and the outcomes of it, if necessary, have been implemented.

Obviously, this has an impact on the bankability of the project, but escalated disputes may have a comparable (or even worse) impact that may lead to complete discontinuation of the project and divestment. Escalation often makes reparation of workable relationships with local communities impossible and scares off new investors. Thus, early prevention of escalation may minimise the risk of huge losses on the project and reputational damage, and this is also in the interest of DFIs and host governments. Furthermore, effective grievance mechanisms are at the core of the Equator Principles and of the OECD Guidelines for Multinational Enterprises, and thus should be an incentive for (Equator Principles) banks and DFIs to engage in such a mechanism or to promote it in their project advisory role. The same goes for governments, as UNGP 28 holds that states should facilitate access to effective non-state-based grievance mechanisms. ${ }^{29}$

Thus, the remedy ecosystem is likely to require a dialogue-based solution that involves all relevant actors and not only the operating entity, and could, for example, provide a solution that includes the agreement of all relevant actors. This may, for example, be postponement of the completion date. This also provides a disincentive for actors to shift responsibilities to other actors involved. It may be important to develop these comprehensive dialogue-based mechanisms in such a way that they are compliant with UNGP 31. This, amongst others, requires addressing rights-holders in a culturally appropriate and sensitive manner, ${ }^{30}$ for which an independent facilitator may be best equipped. This solution may involve one dialogue-based mechanism or collaboration between (existing) mechanisms. ${ }^{31}$ As local rights-holders are likely to need support and capacity-building in connection with this system and the use of it, the trust fund mentioned before may fund such capacity-building by (local) facilitators and provide funding and guidance in the development of such a dialogue-based mechanism. ${ }^{32}$ It may also fund facilitators involved in the dialogue-based mechanism itself. That said, this function should be clearly separated from the previously mentioned function in connection with the access-to-remedy needs assessments. Obviously, if such an assessment is poorly conducted and raises grievances that are fed into the dispute-resolution mechanism, then the independence of the trust fund may be at stake because it has funded this assessment. Thus, if both functions are performed by the same trust fund, then 'Chinese walls' between these functions are required. Furthermore, financiers may assist in the oversight and monitoring of solutions found in the

\footnotetext{
${ }^{28}$ Cf. OECD (2017), Responsible business conduct for institutional investors: key considerations for due diligence under the OECD Guidelines for Multinational Enterprises, pp. 45, 48, available at https://mneguidelines.oecd.org/RBC-forInstitutional-Investors.pdf; OECD (2019), Due diligence for responsible corporate lending and securities underwriting: key considerations for banks implementing the OECD Guidelines for Multinational Enterprises, pp. 58-60, available at http:// mneguidelines.oecd.org/final-master-due-diligence-for-responsible-corporate-lending-and-securities-underwriting.pdf (both accessed 1 February 2021).

${ }^{29}$ See also ARP III, Annex 1.2(d) stating that governments should encourage the establishment of effective functioning of non-state-based mechanisms.

${ }^{30}$ ARP III, Annex 7.8(b).

${ }^{31}$ See on the need for better collaboration between mechanisms in general ARP III under 6, 9, 24.

${ }^{32} \mathrm{Cf}$. regarding the need for support, see Enabling Remediation, pp. 22, 29.
} 
dialogue. ${ }^{33}$ It is obvious that this type of mechanism may have implications for confidentiality, as DFIs or banks tend to agree upon restrictions with the sponsors or the company operating the project regarding information they may provide externally. This may hamper effective participation in the dialogue-based mechanism by rights-holders. Thus, solutions have to be found to address this issue, for example by adapted contractual arrangements on confidentiality and engagement with rights-holders in collaboration with the sponsor or the company operating the project. $^{34}$

\subsection{Escalation mechanisms through arbitration}

However, even dialogue-based mechanisms including all relevant actors may still not provide full remedy for rights-holders, especially if they are not able to reach agreement with all relevant actors, which seems more likely, as multiple actors with diverging interests are involved. Thus, a credible escalation mechanism may be required to provide binding decisions and remedies that the dialogue-based mechanism may not provide ${ }^{35}$ in order to provide full remedy for rights-holders and prevent a barrier to progression of the rule of law. ${ }^{36}$ Most of the contracts between the financiers and the company operating the project are usually governed by UK law and provide for jurisdiction of UK courts in connection with enforcement backed by an arbitration option. Thus, binding solutions either through national courts or through arbitration are offered, but they do not involve all relevant actors and especially not rights-holders. Thus, these mechanisms are not likely to be of assistance as escalation mechanisms regarding disputes with rights-holders. However, the other actors are used to such mechanisms, so it may be conceivable to extend them to rights-holders as well. Especially arbitration may be feasible, as it, unlike (UK) courts in which foreign governments and DFIs may invoke sovereign immunity, it may include the host government and DFIs as well. ${ }^{37}$ Furthermore, arbitration may offer the specific (local) expertise required and may, for example, also source arbitrators from the nongovernmental organisation (NGO) and business constituencies. ${ }^{38}$ Furthermore, it is more flexible regarding applicable and procedural law (which may, for example, include the OECD Guidelines for Multinational Enterprises ${ }^{39}$ or the IFC Performance Standards ${ }^{40}$ ) and may be better equipped to protect (the interests of) local rights-holders. ${ }^{41}$ Arbitration also has the advantage that parties can decide which issues the tribunal decides on. It may be conceivable that parties cannot agree on a specific issue in the dialogue. This issue may be escalated to arbitration and decided. After this, parties may continue the dialogue and, being bound by the decision in the arbitration, may be able to find a solution. This may prevent costly proceedings on the entire dispute, which is likely to be the consequence if the dispute is left to national (UK) courts. It should also be flexible in allowing the dispute

\footnotetext{
${ }^{33}$ See Enabling Remediation, pp. 29, 30.

${ }^{34} \mathrm{Cf}$. OECD (2019), Due diligence for responsible corporate lending and securities underwriting, pp. 57, 63, available at https://mneguidelines.oecd.org/due-diligence-for-responsible-corporate-lending-and-securities-underwriting.htm (accessed 22 February 2021); and also Bhatt (2020, pp. 87, 186, 193, 194); Enabling Remediation, p. 30.

${ }^{35}$ Cf. ARP III, under 28.

${ }^{36}$ Cf. Enabling Remediation, p. 57 (a questionnaire that put forward the question of whether the operational-level grievance mechanism has a credible appeal mechanism).

${ }^{37}$ This obviously requires the state to acknowledge the legitimacy of arbitration in such cases. Cf. ARP III, under 10.

${ }^{38}$ An example is the binding dispute-resolution system of the Dutch International Responsible Business Conduct agreement, which consists of an independent chair and two members from the NGO and business constituencies respectively. See for this mechanism https://www.imvoconvenanten.nl/en/garments-textile/agreement/complaints (accessed 1 February 2021).

${ }^{39}$ Available at http://www.oecd.org/daf/inv/mne/48004323.pdf (accessed 1 February 2021).

${ }^{40}$ Available at https://www.ifc.org/wps/wcm/connect/topics_ext_content/ifc_external_corporate_site/sustainability-at-ifc/ policies-standards/performance-standards/performance-standards (accessed 1 February 2021).

${ }^{41}$ See for an example of such arbitration rules the Hague Rules on Business Human Rights Arbitrations, available at https:// www.cilc.nl/cms/wp-content/uploads/2019/12/The-Hague-Rules-on-Business-and-Human-Rights-Arbitration_CILC-digitalversion.pdf (accessed 1 February 2021). For example, retaliation against rights-holders should be prevented, also by governments, rights-holders should have proper access to information and outcomes should be rights-compatible. Cf. APR III, Annexes 8.9(b), 10.2, 10.3, 12.2, 13.2.
} 
to go back and forth between dialogue and arbitration to decide on issues not agreed upon and being referred to dialogue after this. Furthermore, it is important to provide an independent arbitral tribunal and, thus, it may not be preferable to embed it in DFIs or even the World Bank. ${ }^{42}$ An independent institution like the Permanent Court of Arbitration in The Hague administering these arbitrations seems preferable. ${ }^{43}$ As to funding of arbitration in connection with representation of rights-holders (and potentially of the arbitrators), the aforementioned trust fund may provide funding if it considers escalation meritorious.

However, arbitration implies that the contractual framework on which project finance is built should include third-party rights for local rights-holders to engage in or even instigate arbitration against the contractual parties as an escalation mechanism of the dialogue system. ${ }^{44}$ Such third-party rights are challenging, especially also under UK law, and require further elaboration. ${ }^{45}$ The one thing that can be said is that it would probably require a very clear description and delineation of the group of rights-holders who qualify as third-party rights-holders, bearing in mind that human rights impacts may vary and emerge during different phases of the project life-cycle. It is important to note that the delineation of the rights-holder group should not be too strict, as many potential disputes and their consequences may be overlooked if it is. The initial access-to-remedy needs assessment may be of assistance to define this group.

\section{Conclusion}

In the foregoing, I have described some of the challenges that contractual frameworks in project finance pose to the enjoyment of the rule of law for local rights-holders, especially in connection with their right to access to remedy. This contribution has aimed to develop initial food for thought on the improvement of access to remedy for rights-holders in connection with project finance.

It has been elaborated on that financiers and other actors need clear, consistent and coherent information on the access-to-remedy needs of local rights-holders, which should be assessed before the project starts. It would be conceivable that the project sponsor provides this information in the PIM. Banks may also advise this in their project advisory role. As such an assessment would require meaningful consultation of and interaction with the local rights-holders, a (local) independent facilitator may be needed. In order to realise this and fund such an assessment, it is advised to establish a global (blind) trust fund capitalised by sponsors of the project. Being involved in these assessments regularly, the trust fund is able to provide guidance too. After this assessment, the access-to-remedy needs still lacking need to be bridged. A common challenge is that existing mechanisms include one or two relevant actors, but not all relevant actors. Thus, they cannot provide a remedy that includes all actors. Thus, establishment of a (local) dialogue-based mechanism is needed that includes all relevant actors. As it is less likely that all actors will agree on a solution, a credible escalation mechanism is required. Arbitration may perform this function but necessitates the establishment of third-party rights in the project-finance contracts, which is challenging but not impossible. The aforementioned trust fund may play a role in funding arbitration and the representation of rights-holders in such arbitrations, albeit this function should be clearly separated from the previously mentioned function to maintain independence.

Obviously, these initial observations require further elaboration and piloting, but I hope to have provided food for though and discussion to improve access to remedy for rights-holders in project finance and to progression of the rule of law in such projects.

\section{Conflicts of Interest. None}

\footnotetext{
${ }^{42}$ Cf. ARP III, under 28.

${ }^{43}$ Cf. ARP III, Annexes 7.5, 7.6.

${ }^{44}$ Arbitration should only be an option for the rights-holders and not be used as an obligatory escalation mechanism. Thus, they may choose arbitration, but may also pursue other avenues for escalation if available.

${ }^{45} \mathrm{Cf}$. in connection with corruption Makinwa (2012, pp. 330ff.).
} 
Acknowledgements. The author expresses his gratitude to Maartje van Putten (chair Dutch National Contact Point and former member of the Worldbank inspection panel), Mercedes Sotoca and Arnaud Cohen Stuart (ING) for their valuable suggestions regarding a previous version of this contribution.

\section{References}

Bhatt K (2020) Concessionaires, Financiers and Communities: Implementing Indigenous Peoples' Rights to Land in Transnational Development Projects. Cambridge: Cambridge University Press.

Makinwa A (2012) Private remedies for corruption. Unpublished PhD thesis, Eleven, Rotterdam-The Hague.

Van Putten M (2008) Policing the Banks: Accountability Mechanisms for the Financial Sector. Montreal: McGill-Queen's University Press.

Cite this article: Scheltema M (2021). Access to remedy in transnational development projects: the need for effective and comprehensive remedy ecosystems. International Journal of Law in Context 17, 136-144. https://doi.org/10.1017/ S1744552321000082 